\section{$=$ Literature}

I have not been able to find in the literature any references to the immediate pliysiological action of chlorine. 'ilic inost exact work on the effects of respiring mixtures of chlorine and air is that of Lelımann, ${ }^{2}$ who placed animails during one to six hours in atmospheres contain. ing fioum 1 part per $1,000, \mathrm{CO}$ to 1 part per 1,000 . He foúnd that prolonged exposure to 1 part in 100,000 is sufficient to produce pulmonary haemorrhage and oedema-which lic regards as inflammatory - whilst exposure to 1 part in 10,000 causes in addition a fibrinous ("croupous") exuda. t:on in all thie air passages, evein the finest, and appears ultimately to produce asphyxiation. Numerous experimental patliologísts, "including "Welch, ${ }^{3}$ S." Máyer, ${ }^{4}$ Sahli, and Lowit ${ }^{6}$ have endea roured to elucidate tlie conditions of production of pulmonary ocdema. 'These conditions liave also lately been studied in the "surviving "lung in Magnus's laboratory at"Utreclit by Modrakowski. ${ }^{7}$ In these last-mentioned papers the literature of the subject is given, but most of the work referred to has but little bearing upon the oedema produced by chlorine. Binz ${ }^{8}$ found in the frog that exposure to chlorine gas has no influence on the heart (as against Falls), nor on muscle and nerve, nor on the spinal cord, but believes that it is cárried to the brain, in which, he states, it can be detected by the smell! I have not noticed any smell of chlorine rost mortem in the animals I have dealt with.

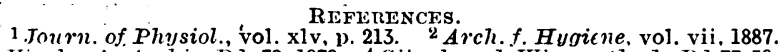
'Virchow's Archiv, Bd. 72, 1878. 'Sitz.-ber. d. Wiener Akad., Bd.77-78, 1878. '5 Arch. f. exp. Path. u. Phar., Bd. 19, 1885. 6 Beitr. z. path. Anat Bd. 14, 1893. 7 Pfliiger's Arch. f. Physiol.; Bd. 158, 1914, pp. 509, 527.

\section{TREATHENT OF GAS POISONING IN TRANSVAAL MINES.}

$\mathrm{BY}$

AxtDREW H. WAT'I, M.B., F.R.C.S.Edin., AND

LOUIS G. IRVINE, M.A., M.D.EdrN., simmen aND JACK hospital, Germiston, transvaA.

C.sses of poisoning by nitrous fumes are not uncommon in tire mines of the Witwatersrand, and from published descriptions of "gassing" in the trenches the syimptoms appear to be very similar.

"Gassing" as it occur's here is due

(1) To the inlialation of gases tormed as the result of burning blasting gelatine. 'I'hese gases consist mostly of the oxicles of nitrogen.

(2). To the inlualation of gases formed by the more or less complete detonation or explosion of blasting gelatine. 'These gases consist chiefly of carbon dioxide and sometimes carbon monoxide.

The inlialation of (1), even in small quantity, is frequently followed by delayed symptoms, and, unless treated as described below, may cause death within twenty-four lours. "This form of "gassing" is apparently very similar to that caused by the inhalation of the asphyxiating gases used by the enemy. The inhalation of (2) may cause no serious symptoms beyond the immediate ones of asphyxia and unconsciousness, and if the patient is rescued in time he recovers without liaving developed any secondary symptoms. The symptoms are due to the inhalation of $\mathrm{CO}$ and $\mathrm{CO}$.

A man who has inlualed the fumes of burning gelatine may present very few symptoms beyond a little headache, cough and tightness of the chest, which soon pass off. In from six to eight hours he begins to have difficulty in breathing and coughs up large quantities of bloody serous fluid and dies of asphyxia and heart failure (delayed nitrous fumes poisoning).

Post mortem there is marked congestion and oedema of the lungs. The mucous membrane of the trachea and larger bronclii is injected. The abdominat veins are greatly enlarged and engorged with dark tarry blood. We have had the blood examined, and have never found any nitric compounds, nor has $\mathrm{CO}$ been found by spectroscopic analysis. The cause of the symptoms is the inhalation of nitrous fumes.

\section{Treatment.}

Every man who lias been exposed to nitrous fumes must be lept under observation, in lospital if possible, for at least twenty-four liours. An emetic of copper sulphate gr. 8 followed by a large quantity of water, is given, or a liypodermic injection of apomorphine. It is inperative that vomiting should be freely induced. If an emetic is given early, any other treatment except rest in bed. for a day is not usually required. The onset of dyspnoea and cyanosis is watched, and should moist sounds develop at the bases of the lungs bloodletting is emplovel, and as much as a pint may be withdrawn fyom a vein in the aru. This is usually diffticult, as the blood is, tarry, and coggu. lates very rapidly. We have transfused with saline to replace some of the blood withdiawn. Atropine may be given hypodermically. Inhalation of oxygen is a!so useful.

Should symptoms of general oedema of the lungs develop, the prognosis is extremely grave. Very few recover when this stage lias been reaclied.

To illustiate the efficacy of treatment, the following case is quoted: In one of the mines under the care of one of us a case of gelatine was accidentally set on fire. 'Tlie fumes spread through the workings, and fourteen men were "gassed." Thirteen of them immediately had an emetic, and the next day were all out of danger. One man disobeyed orders, and went howe without receiving an emetic. He was sent for, but he had gone out for a stroll after having partaken of a liearty luncheon. Ho was found four hours after the accident, and canie to hos. pital uncler protest, stating that he felt quite well. In the evening lie developed general oedema and congestion of his lungs, and died before morning.

These notes are,written in the hope that they may be useful to those treating cases of "gassing" in the trenches

\section{SOME RESULTS OF GERMAN GAS POISONING.}

BY

WALTER BROADBENT, M.D., M.R.C.P., MAJOR R.A.M.C.(T.).

Cases of gas poisoning rarely arrive in this conntry until all the acute symptoms are over, but in the first days of the use of gas two men came under miy care who had only been gassed a few days before. Their chests were full of fine moist râles, and there was great dyspnoea. Oxygen they did not. like, but compoind tincture of benzoin in a steam-lrettle gave some relief. 'The thing. howerer, which did far and away most good was a big linseed poultice over the whole back. 'The men constantly asked for the poultice to be repeated.

On admission neither of these men had any albumin in the urine, but a few days latei in one of them albumin appeared and rapidly increased in quantity, the urine becoming very scanty. Epithelial and granular casts were present in abundance. The legs became oedematons and the face puffy. There was no rise of teniperature. All the moist sounds in the lungs had in the meantime cleared up. The man was in the hospital for two months with very little improvement in the reval condition, and the oedema was still present. He then wished to be transferred to a hospital near his home.

Since then I have seen three other cases of nephritis in men whio had been gassed. One had uraemic lieadaches and early albuminuric retinitis. Obviously nepliritis is one of the deadly sequelae of this gas poisoning.

In my other early acutè case all physical signs in the lungs cleared up, and yet, when the mán began to get out. of bed, he was intensely short of breath. He was kept in: hospital some time, being sent out in a bath-chair erery day, but lie could never walk more than about two miles an hour without getting out of breatl. I have at present another man in hospital with the same dyspnoea and no abnormal physical signs, who was treated in France for gas poisoning. 'The condition is very similar to that of a case of 'South African miners' phthisis, which I saw some years ago, and probably fibrosis of the lungs has been caused by the irritant gas. The outlook for these nien must be very bad.

In neither of these cases suffering from dyspnoea was 
there any albuminuria. In three of the cases of albumin uria there was no dyspnoea on walking, and in the other, the original very acute case, there was no way of telling, as he was in bed. It looks as if in some cases the chlorine or bromine damages the lung epithelium so severely that it does not allow absorption in to the general circulation, while in others the gas passes through the lungs without affecting them permanently, but then sets up an acute nephritis.

One other case under my care, the result of gas poisoning is difficult to explain. A well-built man of 24 was rendered unconscious by gas in April. He says that, when he came to, he was lying doubled up with his head between his knees, but he does not think that he was knocked over by shell concussion. Ever since he has suffered from severe attacks of pain in the upper chest, radiating down the left arm. These are relieved by amyl nitrite and trinitrin, and are true angina pectoris. His pulse is 80 , the vessel of normal thickness and size, and tension is not high. On listening at the aortic cartilage there is a loud rough systolic murmur and a fair second sound-no diastolic nurmur. 'The systolic murmur' is loud along the course of the aorta to the left second space, and is heard in the carotids. The apex beat is in the fifth space in the vertical nipple line, the impulse is fair. There is a good first sound, a slight systolic murmur not conducted out wards, and a second sound; $x$ rays show no enlargement of the aorta. There is no history. of rheumatisn or of syphilis, and the man was perfectly fit up to the day he was gassed. My impression is that he ruptured one of the cusps of the aortic valve in his struggle for breath.

\section{THE ISOLATION OF TYPHOID AND PARA- TYPHOID BACILLI FROM FAECES,}

With Speclal Reference to the Use of Brilliant Green and Telluric Acid.

$$
\text { BY }
$$

C. H. BROWNING, M.D., D.P.H.,

AND

L. I. D. THORNTON, B.A., M.R.C.S., L.R.C.P.

(From the Bland-Sutton Institute of Pathology, the Middlesex Hospita1.)

THE methods for the identification of the various organisms belonging to the typhoid coli group which cause epidemic disease by infection proceeding from the alinentary canal have now been well established." As a preliminary to identification, however, it is necessary to isolate the suspicious organisms in pure culture from the infected subject. In the case of urine this is usually simple, provided that the patient is excreting organisms at the time of examination. When dealing with faeces it may be a matter of considerable difficulty owing to various coliform bacilli being present in great excess over the specific causal organisms. Under ordinary conditions these accompanying organisms tend to overgrow the specific types in culture media. In the early stages of the acute attack of such infections the method of blood culture is, of course, the most important diagnostic procedure, but in convalescent cases, or for the detection of carriers, the faeces and urine must be examined. (The Widal reaction is obviously of extremely limited value as an indication of infection in cases which have recently been inoculated with typhoid or paratyphoid cultures, singly or in combination.)

Unfortunately the argument does not apply that if the specific organisms are so scanty as to be readily missed, then such a case is relatively of only slight importance as a source of infection; on the contrary, it is now well known that the number of specific bacilli in the faeces and urine of a carrier may suddenly undergo marked fluctuations, and a case which is liable to be overlooked at the time of examination on account of the scanty number of organisms present may later on excrete the bacilli in great abundance.

Individuals who excrete these organisms are, of course, a very serious menace to a population unprotected by pro phylactic inoculation; but their danger to an inoculated

* For a comprehensive summary of the differential characters of these organisms see Henderson. Smith, British Medical Journal, these organis. community must not be underrated. It is to be remembered that immunity is only a relative state, and although the strongest proofs of the value of antityphoid immunization have now been afforded, there can be little doubt that a considerable proportion of individuals who have received the customary two doses of vaccine will still be susceptible to a sufficiently massive infection.

For these reasons it cannot be too strongly urged that every means should be adopted to ensure as thorough an examination as possible of the faeces of possible intestinal carriers. Not merely should the faeces be repeatedly examined, + but the most precise methods available for the detection of the specific organisms should be adopted. In cases where the specific organisms are scanty in proportion to the coliform bacilli, the customary method of spreading an emulsion of the faeces on the surface of a solid medium in Petri plates is obviously a somewhat imperfect procedure. In order to obtain a sufficient number of isolated colonies so as to include one of the specific organisms a very large area of medium may require to be inoculated. The media commonly employed, Conradi and Drigalski's, Endo's, and MacConkey's, do not have any effect in reducing the proportion of $B$. coli colonies; the results of Dreyer, Ainley Walker, and Gibson ${ }^{3}$ indicate rather that MacConkey's medium tends to suppress B. typhosus, and they therefore recommend the use of Endo's agar in preference.

A further defect of these media is that various coliform bacilli yield "pale" colonies resembling more or less closely those of the specific organismis, so that much time may be taken up in testing "likely" colonies which are scattered among others. Of course, in cases where typhoid or paratyphoid bacilli are numerous in the faeces any of such media will yield positive results. On the other hand, where the specific organisms form a relatively scanty proportion of the total number of viable bacilli present, the most hopeful means of isolation depends on the use of some agent which, while suppressing the others, will permit the typhoid and paratyphoid bacilli to proliferate. According to the results of Dreyer, Walker, and Gibson, ${ }^{3}$ ultra-violet light produces this effect, and they have recently described a most ingenious procedure whereby, after a plate has been inoculated with the emulsion of faeces, the contaminating organisms are killed off by gracluated exposure to ultra-violet ray's, whereas the typhoid bacilli survive and subsequently produce colonies when the plate is incubated.

Browning, Gilmour, and Mackie, ${ }^{1}$ while investigating the antiseptic properties of a series of benzol dyes, found that "brilliant green" possessed a very marked differential action on organisms of the typhoid-coli group. Thus, in confirmation of Conradi, strains of $B$. typhosus were shown to be in general much more resistant to the action of this dye than were the common members of the coli group; B. proteus is also less resistant than B. typhoosus as a rule; Gaertner's bacillus and paratyphoid bacilli are even more resistant than $B$. typhlosus to brilliant green.

The differential antiseptic power of brilliant green for the typhoid-coli group surpasses that of malachite green, and the former compound exhibits the property of permitting the growth of the specific typhoid-paratyphoid pathogenic organisms while inhibiting other coliform bacilli in a more marked degree than any other substance so far investigated. Gram-positive cocci, of course, aro suppressed by it. Conradi and other workers had already employed brilliant green for the isolation of B. typhosus, but apparently without effecting any marked improvement on previous methods. Thus a solid medium was employed, and this is always disadvantageous if the specific organisms are scanty, since they will occur only where the plate is richly inoculated. Now rich inoculation tends to annul the antiseptic effect, and in consequence the contaminating coliform organisms are enabled to grow exactly where their presence will obscure the typhoid bacilli. In consequence, we recommended the use of brilliant green in fluid medium, a series of tubes of peptone water being employed, to which varying amounts of brilliant green were added; each was inoculated with an emulsion of the faeces, and after twenty-four hour's' incubation at $37^{\circ} \mathrm{C}$. subcultures were made on a solid medium In regard to the general problems of trphoid and paratyphoid
carriers see Ledingham and Arkwright's :The Carrier Problem in Infectious Diseases, London, 1912 .

$\mp$ Dysentery bacilli are not specially resistant to brilliant green hence the method will not apbly to the isolation of these organisus. 